\title{
BMJ Open Risk factors for mental workload: influence of the working environment, cardiovascular health and lifestyle. A cross-sectional study
}

\author{
María Luisa López-López,, Serafín Balanza-Galindo,, ${ }^{2}$ Tomás Vera-Catalán, ${ }^{2}$ \\ Juana Inés Gallego-Gómez, ${ }^{2}$ María Teresa Rodríguez González-Moro, ${ }^{2}$ \\ José Miguel Rivera-Caravaca, ${ }^{2,3}$ Agustín Javier Simonelli-Muñoz ${ }^{2}$
}

To cite: López-López ML, Balanza-Galindo S, VeraCatalán T, et al. Risk factors for mental workload: influence of the working environment, cardiovascular health and lifestyle. A crosssectional study. BMJ Open 2018;8:e022255. doi:10.1136/ bmjopen-2018-022255

- Prepublication history and additional material for this paper are available online. To view these files, please visit the journal online (http://dx.doi. org/10.1136/bmjopen-2018022255).

Received 22 February 2018 Revised 3 September 2018 Accepted 20 November 2018

Check for updates

(C) Author(s) (or their employer(s)) 2018. Re-use permitted under CC BY-NC. No commercial re-use. See rights and permissions. Published by BMJ.

For numbered affiliations see end of article.

Correspondence to

Dr Agustín Javier Simonelli-

Muñoz; agsimonelli@ucam.edu

\section{ABSTRACT}

Objectives Mental workload is a condition which can negatively influence the overall health of workers. In this study, we aimed to investigate the risk factors for the onset of mental workload, including working conditions, cardiovascular comorbidities and lifestyle habits, in a working population.

Methods This is a cross-sectional study including 408 workers from a risk prevention service of small/medium companies in Murcia (Spain). Workers from the secondary and tertiary sectors or primary/secondary sectors with administrative management tasks who underwent a routine medical examination between 1 January 2017 and 31 April 2017 were included. Workers from the primary sector and construction were excluded to avoid a sex and age bias.

Results From 408 workers, 206 (50.5\%) were females; with mean age $36.8 \pm 10.4$ years. 164 (40.2\%) workers had a moderate to significant risk of mental workload. Based on multivariate logistic regression analyses, independent predictors of mental workload were age $\geq 30$ years (OR 2.42, 95\% $\mathrm{Cl} 1.22$ to $4.80 ; \mathrm{p}=0.012$ ), working in tertiary (OR $7.89,95 \% \mathrm{Cl} 3.59$ to $17.31 ; \mathrm{p}<0.001)$ or administrative sectors (OR $87.57,95 \% \mathrm{Cl} 35.22$ to 217.79 ; $\mathrm{p}<0.001)$ and alcohol consumption (OR 2.08, 95\% Cl 1.16 to $3.73 ; p=0.014$ ). Smoking habit (OR $0.47,95 \% \mathrm{Cl} 0.26$ to $0.85 ; p=0.012$ ) was found as a protective variable so nonsmoking was considered as a risk factor.

Conclusion In the present study from a risk prevention service including workers of small/medium companies from the secondary and tertiary sectors and workers with administrative tasks, the labour sector, age, alcohol consumption and smoking habits, are independently associated with a higher risk of developing moderate to significant mental workload.

\section{INTRODUCTION}

The mental load is the result of the influence of external factors that mentally affect the human being. It is, therefore, a complex interaction between individual, technical, organisational and social factors. ${ }^{1}$ The mental load uses to be higher in works involving

\section{Strengths and limitations of this study}

- This is a cross-sectional study including workers attending routine medical examinations between 1 January 2017 and 31 April 2017 in a risk prevention service of small/medium companies in Murcia (Spain).

- Only workers from the secondary sector, tertiary sector and workers from the primary or secondary sectors with administrative management tasks were included.

- This study identifies independent risk factors for moderate to significant mental workload, which allows the identification of those workers with higher risk in order to perform prevention interventions and health campaigns.

- The inclusion of workers only from the secondary and tertiary sectors may hinder the generalisability of the results to the first sector.

- As this was an exploratory study, the results reported are based on a post hoc analysis and should be regarded as hypothesis generating so prospective studies are necessary to validate our results.

cognitive processes, information processing and affective aspects such as tasks requiring high mental concentration, attention, memory, coordination, decision-making or emotional self-control. ${ }^{2}$ However, the mental load depends on the quantity and quality of the information, and it increases as the complexity of the information does. ${ }^{3}$ On the other hand, the mental load can also rise with repetitive, monotonous and hypovigilant works, in which the worker reaches a state of saturation, drowsiness and decreased reaction capacity.

It is well known that some psychosocial factors and ergonomic factors at work can affect the psychosocial health of the worker causing an excessive increase in the mental load. ${ }^{4}$ 
During the last years, the interest of the impact of cardiovascular health on the mental workload is also increasing. However, there is a lack of evidence about cardiovascular diseases and the relation with occupational health, given that these are often perceived as a non-occupational problem. The belief that they do not directly affect the interests of organisational productivity and their conception as a responsibility related to public health has translated into a scarce investigation of the relationship between cardiovascular disease and occupational factors. ${ }^{5}$ Thus far, there are studies analysing cardiovascular risk factors in the working population, but these were performed for purely descriptive or for preventive aims to establish educational health programmes. Often, as a possible aetiology, occupational features are obviated. ${ }^{6-9}$

For this reason, the need to study workers' mental workload from different perspectives is evident. ${ }^{10}$ The aim of the present study was to investigate risk factors for the onset of mental workload, including working conditions, cardiovascular comorbidities and lifestyle habits, in a working population from the secondary and tertiary sectors or with administrative tasks.

\section{METHODS}

This is a cross-sectional study that included all workers from small/medium companies in Murcia (Spain) in which a medical examination by the risk prevention service was carried out. Only workers who attended routine medical examinations performed between 1 January 2017 and 31 April 2017 were recruited. To be included in the study, the workers must be active in the secondary sector (manufacturing and industry) or tertiary sector (services). Subjects working on the primary sector or secondary sectors but with tasks concerning the tertiary sector such as administrative management were also included. In the present study, this group has been named as 'administrative group'. Workers from the primary sector (extraction of raw materials) and construction were excluded to avoid the bias of sex and age, due to the high proportion of men working in these sectors.

At inclusion, information regarding sex, age and related to work activity such as labour sector, company size, seniority in the workplace and working hours was recorded. Also, lifestyle habits such as smoking, alcohol consumption and exercise have been considered. Blood pressure, heart rate, lipids (total cholesterol, high-density lipoprotein cholesterol, low-density lipoprotein cholesterol and triglycerides), uric acid, glucose and body mass index (BMI) have also been collected. Given the cross-sectional design of the study, all data were obtained from the database of a risk prevention service at inclusion. Thus, no follow-up was performed. Ergonomic risk factors for the mental workload were assessed using the "Manual for the Assessment and Prevention of Ergonomic and Psychosocial Risks in Small/Medium Sized Companies ${ }^{\text {11 }}$ :

Item 1: 'The work is based on information processing.'
Item 2: 'The task requires a high level of attention.'

Item 3: 'The work has little content and it is very repetitive.'

Item 4: 'Mistakes and breakdowns frequently appear at work.'

These items were answered as yes/no. For the present analysis, we designed a new variable (named as overall mental workload) assuming that each item answered as 'yes' summed 1 point. Thus, this new variable was obtained from the sum of the four items, with values ranging from 0 to 4 . A score of 0 was considered as a trivial risk of overall mental workload, whereas scores of 1-2; 3 and 4 were considered as a tolerable risk, moderate risk and significant risk, respectively. For statistical analyses, we also dichotomised this variable as follows: 'trivial-tolerable risk of mental workload' (score 0-2) and 'moderate-significant risk of mental workload' (score 3-4).

The appropriate permissions of the risk prevention service were obtained before the beginning of the study. Given that the information and all data were anonymised (ie, we had no access to names or other personal details), informed consents were not obtained.

\section{Patient and public involvement}

This is a cross-sectional study in which all data were recorded from a medical examination in a risk prevention service. Therefore, we had no contact with patients, given that at the moment of data collection, all patients had already attended this service. For this reason, patients included were not directly involved in the development of the research question and outcome measures, nor the recruitment and design of the study. The study results will be sent-when published-to the risk prevention service for dissemination to the participants.

\section{Statistical analysis}

Categorical variables were expressed as frequencies and percentages. Continuous variables were tested for normality by the Kolmogorov-Smirnov test and presented as mean $\pm \mathrm{SD}$ or median and IQR, as appropriate.

The Pearson $\chi^{2}$ test was used to compare proportions.

Logistic regressions were performed for univariate analyses and for multivariate adjustment. Multivariate models were performed including only those variables with a $\mathrm{p}<0.15$ in the univariate analysis. Results are presented as ORs and $95 \%$ CIs.

A $p<0.05$ was accepted as statistically significant. Statistical analyses were performed using the SPSS V.18.0 for Windows (SPSS).

\section{RESULTS}

We included 408 workers with a mean age of $36.8 \pm 10.4$ years. From the overall population, $206(50.5 \%)$ were females, which means that the cohort was balanced between both genders. 
The average working hours were 37.6 hours/week and the average job seniority was 8.4 years. The distribution of the workers based on the work activity yielded three groups: $35.5 \%$ of participants worked in the tertiary sector, $35 \%$ worked in the secondary sector and $29.4 \%$ had administrative tasks. With respect to the company size, $13.7 \%$ of the companies had less than 7 employees, $43.9 \%$ were companies with 7-49 workers and $42.4 \%$ were companies with 50-249 employees. In addition, $73.5 \%$ of workers were in a company of with $>12$ workers.

Regarding lifestyle-related habits, we found that $42.6 \%$ of workers did not perform any physical exercise whereas $46.3 \%$ performed it regularly (at least 1 hour of physical exercise weekly out of the working hour). Additionally, $7.4 \%$ of the participants were former smokers and $15.3 \%$ were current smokers. Referring to alcohol consumption, the mean grams of alcohol consumed was $9.03 \pm 28.9$, and $57.6 \%$ reported weekly consumption. In addition, only $3.5 \%$ of those workers who reported regular alcohol consumption acknowledged an intake $>100$ g per week.

Concerning cardiovascular comorbidities, $18.9 \%$ of the workers had hypertension, $41.4 \%$ had hyperlipidaemia, 3.2\% had diabetes and 9.3\% had hyperuricaemia. Importantly, $13.5 \%$ of workers had obesity and $33.1 \%$ had overweight based on the BMI. These data, as well as other vital signs and blood parameters, are shown in table 1.

With regard to risk factors for mental workload according to the 'Manual for the Assessment and Prevention of Ergonomic and Psychosocial Risks in Small/Medium Sized Companies', item 2 was the most common, followed by item 3 and item 1 . Item 4 was the less commonly reported risk factor (figure 1). Based on the risk categories that we established, $2(0.5 \%)$ subjects had a trivial risk, $242(59.3 \%)$ had a tolerable risk, 146 (35.8\%) had a moderate risk and finally, 18 (4.4\%) showed a significant risk. By distributing these results into dichotomic categories, we found that 244 (59.8\%)

Table 1 Baseline characteristics

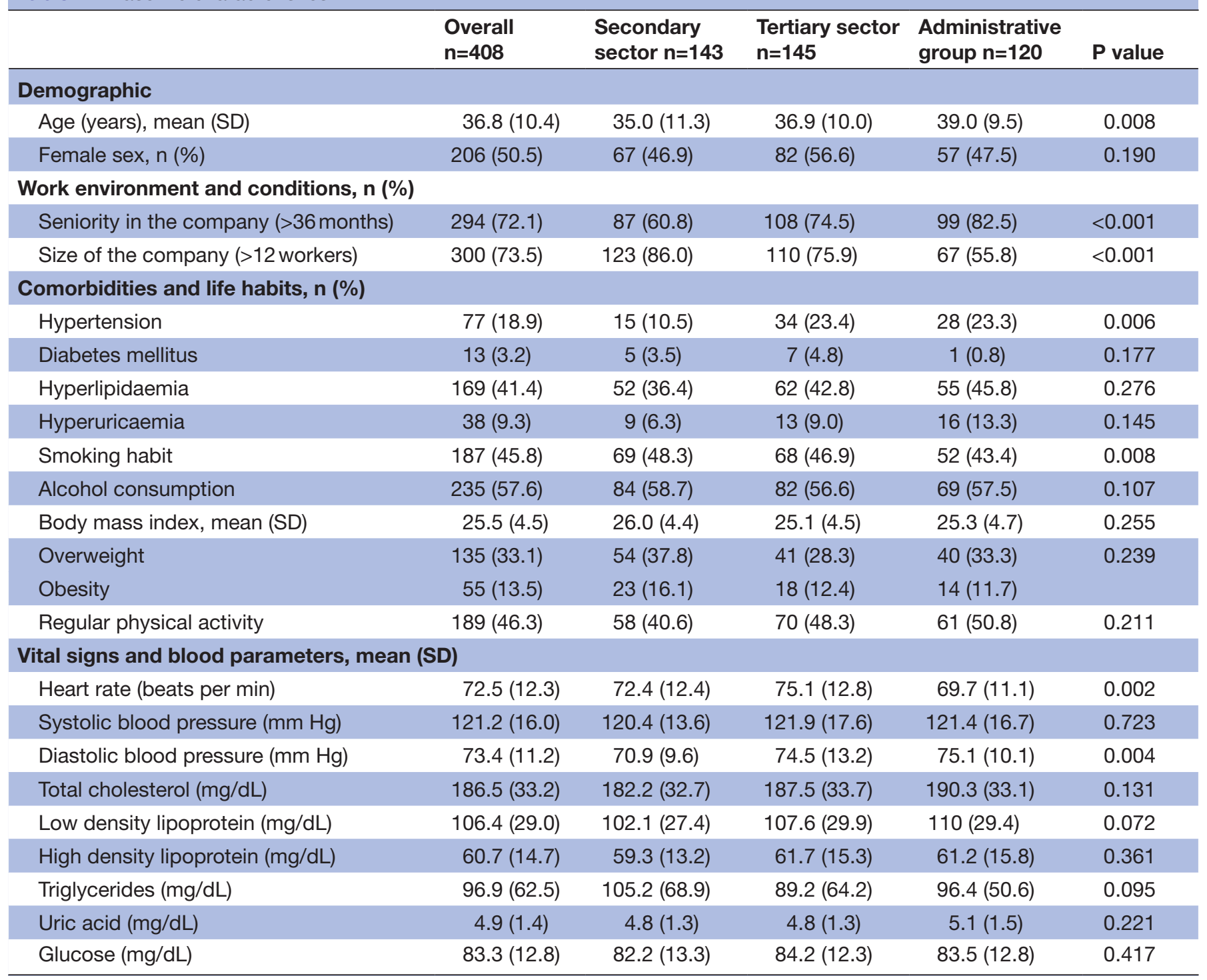




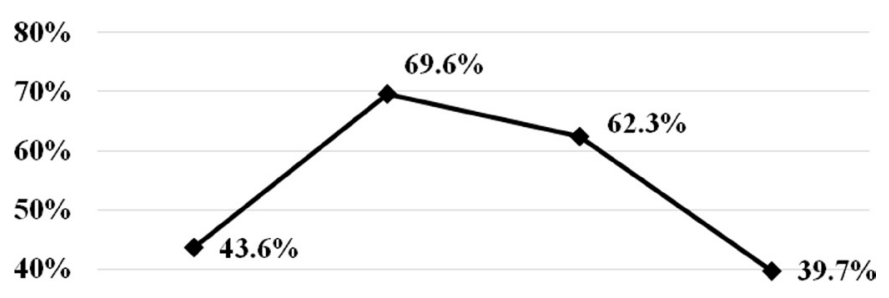

$30 \%$

$20 \%$

$10 \%$

$0 \%$

Item 1 Item $2 \quad$ Item $3 \quad$ Item 4

Figure 1 Ergonomic risk factors for mental workload.

workers had a 'trivial-tolerable risk of mental workload' and $164(40.2 \%)$ had 'moderate-significant risk of mental workload'.

\section{Univariate and multivariate analyses}

Univariate and multivariate analyses are shown in table 2. These analyses included variables from the work environment, cardiovascular comorbidities and lifestyle habits. After the multivariate adjustment, the independent predictors of moderate-significant risk of mental workload were age $\geq 30$ years (OR 2.42, 95\% CI 1.22 to 4.80; $\mathrm{p}=0.012$ ), working in tertiary (OR 7.89, 95\% CI 3.59 to $17.31 ; \mathrm{p}<0.001$ ) or administrative sector (OR 87.57, $95 \%$ CI 35.22 to $217.79 ; \mathrm{p}<0.001)$ and alcohol consumption (OR 2.08, 95\% CI 1.16 to 3.73; p=0.014). Smoking habit (OR $0.47,95 \%$ CI 0.26 to $0.85 ; \mathrm{p}=0.012$ ) was found as a protective variable so non-smoking was considered as a risk factor (table 2). Subanalyses of risk factors for mental workload in each group (secondary, tertiary and administrative) have been included in online supplementary tables 1-3.

\section{DISCUSSION}

In this study, we found that the labour sector, age, smoking habits and alcohol consumption are independent risk factors for the development of moderate to significant mental workload. These results help us to define the profile of the workers most exposed to mental workload in our environment, which is particularly interesting to perform effective prevention and health campaigns.

Of note, according to the 'Manual for the Assessment and Prevention of Ergonomic and Psychosocial Risks in Small/Medium Sized Companies', the vast majority of workers $(99.5 \%)$ were exposed to at least one risk factor for the mental workload in the work environment. Thus, the prevalence of risk factors for the mental workload in our study is quite high, which contrasts to the data reported by VII National Survey on Working Conditions ${ }^{12}$ and the study of González Guitierrez et al. ${ }^{13}$ This emphasises the relevance of conducting a study to investigate factors leading to increasing the risk of mental workload.

The risk of mental workload has been linked to occupational features in several studies. ${ }^{14}$ For example, a previous study carried out with workers from the tertiary sector showed that more than half of these workers suffered a high mental workload. ${ }^{16}$ In our study, the group with higher risk of moderate to significant mental workload was the administrative group. This group of workers is composed mainly of subjects who require higher qualification to practice their job. Thus, the responsibility of these workers is often higher compared with the rest of workers leading to higher level of stress which could contribute to increase the risk of mental workload. ${ }^{17}$

Another result that requires future in-depth analyses is the relationship between moderate to significant mental workload and age. To the best of our knowledge, this is the first study showing that workers older than 30 years

Table 2 Risk factors for moderate to significant mental workload by univariate and multivariate logistic regression analyses

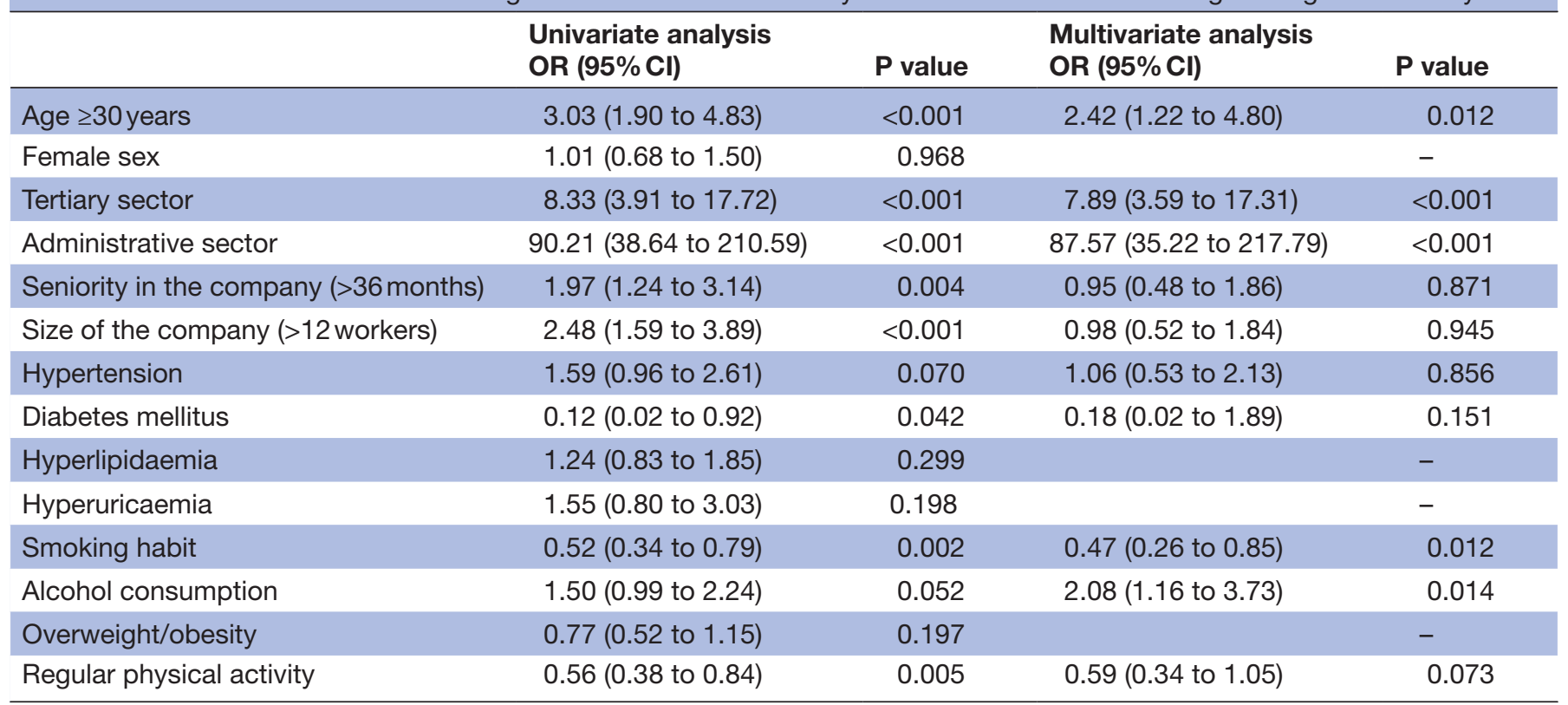


are at higher risk of mental workload. In our opinion, this is an issue that will need further investigation in the future.

On the other hand, two life habits were associated with mental workload; alcohol consumption and smoking habit. Alcohol consumption increased the risk of mental workload in the present study more than twofold. These results are in accordance with those obtained in a study conducted by Melia and Batería Valencia. ${ }^{18}$ Indeed, the negative influence of alcohol in work environments is well known, not only over the risk of mental workload but it also affects productivity, causing significant damages to employers and workers due to absenteeism, work misalignments, work disabilities, staff turnover, reduced work performance and poor quality of work. ${ }^{19} 20$

More difficult to clarify is the fact that non-smoking workers have a higher risk of mental workload. However, the administrative group had the highest risk of moderate to significant mental workload and as we commented above, this population had a higher qualification. Therefore, those workers most affected by the mental workload are workers with the high level of education, which in turn is usually associated with higher knowledge about health and healthy lifestyles compared with workers with the lower level of education or lower socioeconomic levels. $^{621}$

The risk profile for a mental workload of workers from the secondary and tertiary sectors has been identified in this study and in the light of our results; the need of prevention and health promotion actions is evident. In particular, some interventions should focus on avoiding smoking habits and alcohol consumption as well as practice physical exercise. Interventions, such as information in the Occupational Health Nursing and Medicine clinics, detailed analyses of the toxic substances consumption, risk analyses of a mental workload according to the job and group therapies for the acquisition of healthy habits, could be appropriate and useful.

\section{Limitations}

There are several limitations that must be acknowledged. First, the inclusion of workers only from the secondary and tertiary sectors may hinder the generalisability of the results to the first sector. However, as this was an exploratory study, we decided to exclude this sector in order to avoid a gender bias. Second, given the cross-sectional design of the study, the results reported are based on a post hoc analysis and should be regarded as hypothesis generating. Prospective studies with larger cohorts in different settings are necessary to validate our results.

\section{CONCLUSIONS}

In the present study from a risk prevention service including workers of small/medium companies, the labour sector, age, alcohol consumption and smoking habits were independently associated with a higher risk of developing moderate to significant mental workload.

\section{Author affiliations}

${ }^{1}$ Risk Prevention Service in Torrevieja Town hall, Alicante, Spain

${ }^{2}$ Faculty of Nursing, Catholic University of Murcia (UCAM), Murcia, Spain ${ }^{3}$ Department of Cardiology, Hospital Clínico Universitario Virgen de la Arrixaca, Instituto Murciano de Investigación Biosanitaria (IMIB-Arrixaca), Centro de Investigación Biomédica en Red Enfermedades Cardiovasculares (CIBERCV), Murcia, Spain

Contributors MLLL, AJSM, JIGG and SB-G designed the present work and collaborated to data acquisition. TVC and MTRG-M revised the current literature and wrote the first draft of the article. JMR-C performed statistical analyses, drafted and critically revised the manuscript. All authors contributed to and have approved the final manuscript.

Funding Funding for this study was provided by the Catholic University of Murcia (UCAM) (research grant PMAFI/28/14).

Disclaimer The UCAM had no role in the study design neither in the collection, interpretation and analysis of data.

Competing interests None declared.

Patient consent Not required.

Ethics approval The study was approved by the Ethics Committee of the Catholic University of Murcia (UCAM).

Provenance and peer review Not commissioned; externally peer reviewed.

Data sharing statement All data relevant to this manuscript will not be available on acceptance.

Open access This is an open access article distributed in accordance with the Creative Commons Attribution Non Commercial (CC BY-NC 4.0) license, which permits others to distribute, remix, adapt, build upon this work non-commercially, and license their derivative works on different terms, provided the original work is properly cited, appropriate credit is given, any changes made indicated, and the use is non-commercial. See: http://creativecommons.org/licenses/by-nc/4.0/.

\section{REFERENCES}

1. Asociación_Española_de_Normalización_y_certificación. Principios ergonómicos relativos a la carga de trabajo mental. Parte 1: Términos y definiciones generales. Madrid: UNE-EN ISO, 2001:10075-1.

2. De Arquer Pulgar MI. Carga mental de trabajo: factores. Centro Nacional de Condiciones de Trabajo: Barcelona, 1999.

3. Mulder G. The heart of mental effort: studies in the cardiovascular psychophysiology of mental work. University of Groningen: Groningen:, 1980.

4. Mur C, Maqueda J. Occupational health and mental health: state of the art. Med Segur Trab 2011;57:1-3.

5. Juárez-García A. [Psychosocial work factors associated to blood pressure and cardiovascular symptoms among Mexican nurses]. Salud Publica Mex 2007;49:109-17.

6. Zimmermann Verdejo M, González Gómez MF, Galán Labaca I, et al. [Cardiovascular risk profiles by occupation in Madrid region, Spain]. Rev Esp Salud Publica 2010;84:293-308.

7. Martínez B, Arbués E. Prevalencia de los factores de riesgo cardiovascular en trabajadores de los sectores laborales secundario y terciario. Enferm Global 2012;11:31-40.

8. Alonso Díaz JA, Calleja Méndez AB, Borbolla Ruiz S. Prevalencia de los factores de riesgo cardiovascular en trabajadores de una planta metalúrgica. Med Segur Trab 2012;58:269-81.

9. López-González A, Martínez E, Rodríguez M, et al. Prevalencia de factores de riesgo cardiovascular en trabajadores aparentemente sanos. Gac Med Mex 2012;148:430-7.

10. Duró A. Calidad de vida laboral y psicología social de la salud laboral: hacia un modelo de componentes comunes para explicar el bienestar laboral psicológico y la salud mental laboral de origen psicosocial. Fundamentos teóricos. Rev del Minist Trab y Asuntos Soc Ser Econ y Sociol 2005;56:15-56.

11. Instituto-Nacional-de-Seguridad-e-Higiene-en-el-Trabajo. Manual for the assessment and prevention of ergonomic and psychosocial risks in small/medium sized companies: Instituto-Nacional-de-Seguridade-Higiene-en-el-Trabajo, 2002.

12. Almodovar Molina A, Galiana Blanco ML, Hervás Rivero P, et al. VII Encuesta Nacional de Condiciones de Trabajo. Madrid: InstitutoNacional-de-Seguridad-e-Higiene-en-el-Trabajo, 2012. 
13. González Guitierrez JL, Moreno Jimenez B, Garrosa Hernández E, et al. Mental workload and fatigue in special nursing services. Rev Latinoam Psicol 2005;37:477-92.

14. Parent-Thirion A, Biletta I, Cabrita J, et al. Sixth European working conditions survey - overview report (2017 update). Luxembourg: Publications-Office-of-the-European-Union 2017.

15. Instituto-de-Seguridad-y-Salud-Laboral-de-la-Región-de-Murcia. Consejería-de-Educación -F-y-E. Il Encuesta regional de condiciones de trabajo. Murcia: Instituto-de-Seguridad-y-Salud-Laboral-de-laRegión-de-Murcia.-Consejería-de-Educación,-Formación-y-Empleo, 2011.

16. Díaz Ramiro E, Rubio Valdehita S, Martín García J, et al. Psychometric Study of NASA-TLX Mental Workload Index in a Sample of Spanish Workers. Rev Psicol Trab Organ 2010;26:191-9.
17. Ptáček R, Vňuková M, Raboch J. [Work-related stress and mental health - can work lead to mental disorders?]. Cas Lek Cesk 2017;156:81-7.

18. Melia JL, Batería Valencia P. Foment del treball nacional. Barcelona: Univeridad de Valencia, 2003.

19. Howland J, Almeida A, Rohsenow D, et al. How safe are federal regulations on occupational alcohol use? J Public Health Policy 2006;27:389-404.

20. Ochoa Mangado E. Alcohol consumption and occupational health. Review and lines of action. Med Segur Trab 2011;57:173-87.

21. Sánchez-Chaparro MA, Román-García J, Calvo-Bonacho E, et al. [Prevalence of cardiovascular risk factors in the Spanish working population]. Rev Esp Cardiol 2006;59:421-30. 